\title{
Multispecies Archaeology
}

Edited by Suzanne E. Pilaar Birch

\author{
2018. Routledge
}

Hbk. 376 pp.

ISBN: 9781138898981

Review by Caroline Tully

University of Melbourne

A multispecies approach to archaeology examines the past from a nonanthropocentric perspective. It removes human exceptionalism and seeks to understand what we can learn about the past if we position humans as just one actor among many others, viewing our co-species as agents with their own agendas and trajectories that need not revolve around humans or exhibit human equivalence. In the Introduction to Multispecies Archaeology editor, Suzanne E. Pilaar Birch, explains that a multispecies approach is characterised by a multiplicity of perspectives and influences. Instead of viewing other life forms as background, resources or symbols utilised by humans, a multispecies approach identifies a multitude of entangled agents and relations that include but also exceed those between predator and prey, parasite and host, symbiotic partner, and indifferent neighbour. The subsequent chapters in this book aim to provide detailed accounts of the lifeworlds of other non-human species as well as examine epochal events, such as the beginnings of agriculture and domestication, and the Anthropocene, from a non-anthropocentric perspective. 
Multispecies Archaeology is divided into four parts: "Part I Living in the Anthropocene"; "Part II Multispecies ecology of the built environment"; "Part III Agrarian commitments: towards an archaeology of symbiosis"; and "Part IV The ecology of movement". The first chapter, by Noah Herningman, focuses on scientific precursors to archaeology, in particular the proto-multispecies geological and paleontological theorising of the Enlightenment naturalist antiquarian, George-Louis Leclerc, Comte de Buffon. This is followed by Christopher Witmore's examination of the characteristics of Neolithic farming, which can only be said to have been displaced by modern agricultural and pastoral monoculture as late as the twentieth century after the expansion of fossil fuels, and contrasts it with two examples of contemporary industrialised farming practices. The third chapter, by Thomas P. Leppard, explains that we should not consider the Anthropocene to be an epoch solely resulting from the activities of humans, but rather a consequence of the activities of many species. This is followed by Breana Campbell, Todd J. Braje, and Stephen G. Whitaker's chapter explaining how the use of relatively modern data for establishing marine conservation and restoration biology of marine ecosystems, degraded by human actions and over-exploitation, is flawed. Instead, the time depth management practices needs to be extended through the use of archaeological, palaeobiological, and historical approaches because these provide a picture of marine ecosystems that predate the modern collapse of the world's oceans. Part I ends with Dóra Pétursdóttir's artistic study about a beach in northern Norway that, because of its location in regards to oceanic currents, is a repository for all sorts of oceanic detritus.

In Part II of the book, chapters focus on the multispecies nature of what have traditionally been considered the human domains of architecture and art. Chapter Six, by Gavin Lucas, focuses on the multispecies nature of turf houses in Iceland, identifying the agential role of other non-human species, particularly microfauna such as insects, moulds and bacteria within the structure. In the next chapter, Eva Domanska proposes that abandoned Protestant cemeteries in Poland can be living habitats for multispecies relations between the microorganisms of decay, insects, animals and plants, and advocates transforming old cemeteries into contemporary eco-cemeteries. In Chapter Eight Benjamin Alberti and 
Severin Fowles interpret instances of rock art as multispecies happenings, consequently destabilising the (art)historical position of the "artist". In the following chapter, Victor D. Thompson and Thomas J. Pluckhahn understand anthropogenically constructed shell middens as intentional architecture, rather than simply as refuse heaps. The subsequent chapter, by Michael MacKinnon, investigates zoological evidence from ancient urban sites in the Mediterranean and proposes that human and animal interaction within such spaces involves various participatory and agential interactions. In the final part of this section Chapter 11, by Nimrod Marom and Lior Weissbrid, highlights major developments in the formation of species communities and the manner in which this process interacted with human social organisation.

Part III begins with Terry O'Connor's chapter which analyses ancient and modern DNA to examine the ancient genomic traces of domestication regarding the emergence of modern livestock in order to understand "who benefits?" in regard to the domestication of animals in the Neolithic. Chapter 13 by Kristin Armstrong Oma continues in this vein, focusing on the domestic life of Norwegian longhouses where sheep, sheep dogs and humans co-habited. In Chapter 14 Laura S. Weyrich looks at how bacterial communities within the human body changed during two events in human history: the adoption of agriculture and the industrial revolution. The final chapter of Part III, by Brian Boyd, advocates that we takes seriously the multispecies nature of domestication and see it as co-domestication rather than human mastery over other species and the environment.

Part IV begins with a study by Oscar Aldred which proposes that rather than view animals as below humans as subjects for care, or above us as symbols, that it is more useful to envision them as companions beside us. Chapter 17 , by Nick J. Overton, focuses on the use of rhythm in conjunction with faunal materials to examine the ways in which different engagements and experiences led humans to understand particular species. In Chapter 18 Suzanne E. Pilaar Birch argues for the advantages of niche construction theory as an explanatory paradigm for a specifically multispecies approach that would explain how human and non-human creatures mould their environment through behaviour that takes advantage of intergenerational knowledge, permitting more complex relationships between humans, 
plants, animals, and their environments to be explored in the archaeological record. Chapter 19, by Jamie Hodgkins, Petrus le Roux, Curtis W. Marean, Kirsty Penkman, Molly Crisp, Erich Fisher and Julia Lee-Thorp, examines the role that ostrich play in shaping subsistence patterns in early modern human and brown hyena behaviour, and demonstrates that the behavioural patterns of other living organisms function as powerful forces that shape both human and carnivore behaviour and mobility. The final chapter in the book, by Kate Britton, proposes direct methods for reconstructing prey species' palaeomigratory behaviour in order to better understand faunal movements such as migrations and explains how such behaviours help us understand evolutionary change, speciation and extinction, as well as ancient human behaviours.

So, are the chapters in Multispecies Archaeology successful in examining the past from a non-anthropocentric perspective? Overall they are, although some are more anthropocentric than others, while still being generally "multispecies" approaches. The book covers a range of periods and regions and includes both New and Old World case studies. Each chapter is a fascinating, stand-alone investigation into expanded worlds beyond, and sometimes within, the human. Mainly the language used is straightforward, although some authors use more disciplinary-specific jargon (largely biological and zoological) than others and as a consequence are more difficult for non-specialists to understand. While the book reaches as far back as the Palaeolithic, it brings to the fore questions about the relationship of the Anthropocene and its dating in regard to the Neolithic, which seems to be more unfixed in time than has traditionally been understood. It also asks whether there really is an "Anthropocene" caused solely by humans (anthropos) at all, instead of perhaps a process of change driven by many different species inadvertently working together. Prominent also were the studies on domestication which portrayed humans' role in it as one of controlled predation but explained how herbivorous animals may have perceived this as the lesser evil, faced with the alternative of other non-human predators. While one may initially be sceptical in regard to herbivores' agency in the domestication process, the studies on this topic were thought-provoking and more-or-less convincing. 
The focus of multispecies studies on the lifeworlds of other species is enlightening in itself, but also topples humans from their biblicallysanctioned position at the apex of the pyramid of life and induces both awe and humility, especially in regards to the fact that as well as living within a multispecies world, our bodies are multispecies organisms that host diverse microbial communities. An archaeological approach to multispecies worlds helps us to expand this knowledge within the time dimension, and this may prove to be paradigm-changing within the discipline. Multispecies Archaeology provides a leading example to consider the multispecies perspective when analysing data; the use of this approach goes beyond archaeology (and anthropological ethnography, where it originated) and contributes to the larger project of the Environmental Humanities. 